\title{
Bacillus Cereus isolation and load from raw cow milk sold in Markets of Haramaya District, eastern Ethiopia
}

\author{
Ashebr Abraha ${ }^{1 *}$ (D), Teshome Bikila ${ }^{1,2}$, Sisay Alemu and Yimer Muktar ${ }^{1}$
}

\begin{abstract}
Background: Bacillus cereus is a spore-forming bacterium that is widely distributed in the environment and can be detected in a variety of raw milk and milk products especially in vegetative form, which exposed directly in contact with the soil and produces toxins which caused food borne illness and considered as a significant public health hazard. A cross-sectional study was carried out to determine the prevalence and load of Bacillus cereus vegetative cells in raw bulk milk sold in market places at Bate, Haramaya and Aweday Towns, Eastern Ethiopia as well as to assess the in-vitro antimicrobial susceptibility of isolates. A total of 103 raw milk samples were collected and examined for the presence of Bacillus cereus by using Bacillus cereus selective agar media. The isolated presumptive colonies were further analyzed using standard microbiological methods to confirm the presence of Bacillus cereus. Spreading plate method was employed to count the bacteria from milk samples based on 10 fold serial dilutions. For antimicrobial susceptibility test, the disc diffusion test was employed using commercially available 10 antimicrobial discs.

Results: The overall prevalence's of Bacillus cereus in raw milk samples was 38.8\%. Milk collected from Aweday market showed higher occurrence (46.9\%) than from Bate (40\%) and Haramaya town (31.7\%). Analysis of bacterial count showed that, $60 \%$ of Bacillus cereus positive milk samples were with bacterial load above recommended limit $\left(>10^{5} \mathrm{CFU} /\right.$ $\mathrm{ml}$ ) for human consumption. However, there was no statistically significant difference $(p>0.05)$ on the occurrence of Bacillus cereus and bacterial load among different areas. Based on disc diffusion test, $B$. cereus isolates showed high resistance to Penicillin (100\%), Ampicillin (100\%), Amoxicillin (80\%) and Cefoxitin (80\%).

Conclusion: The study indicated that milk samples from market areas were highly contaminated with Bacillus cereus, with potential risk for human consumption. This suggests the need for effective hygienic measures to be introduced during milk production and distribution to avoid public health hazards.
\end{abstract}

Keywords: Bacillus cereus, Bacterial load, Drug susceptibility, Raw bulk milk

\section{Background}

Bacillus cereus is a facultative anaerobic, motile, grampositive, catalase positive, does not ferment mannitol, rod-shape, beta-hemolytic and spore-forming bacterium; that is widely distributed in the environment due to its ability to resist hostile conditions (Ceuppens et al. 2013) and growth temperature ranging from 10 to $48{ }^{\circ} \mathrm{C}$ with optimal growth between $28{ }^{\circ} \mathrm{C}$ and $35^{\circ} \mathrm{C}$, pH values of 4.9 to 9.3 and water activities of 0.92 to 1.0 (OSPBH 2005).

\footnotetext{
* Correspondence: abraha.ashebr@yahoo.com

${ }^{1}$ Haramaya University College of Veterinary Medicine, P.O. Box 138, Dire

Dawa, Ethiopia

Full list of author information is available at the end of the article
}

Another important trait of Bacillus cereus is their ability to grow at the storage temperature of milk $\left(4-7{ }^{\circ} \mathrm{C}\right)$, which mainly determines the shelf life of pasteurized milk and derived milk products (TeGiffel et al. 1995; Granum 2005).

Bacillus cereus is commonly present in food production environments by virtue of its highly adhesive endospores, spreading to all kinds of foods. It produces a range of virulence factors that may cause unpleasant disease in humans when present in food or the gastrointestinal tract and it is one of the major food-borne pathogenic bacteria, although in most cases disease is mild and of short duration. Interestingly, the spectrum of potential $B$. cereus toxicity ranges from strains used as probiotics for humans to highly toxic 
strains reported to be responsible for food-related fatalities (Hong et al. 2005). The unique nature of Bacillus cereus like heat resistance, endospore forming abilities, toxin production and psychrotrophic feature (ability to growing below $7{ }^{\circ} \mathrm{C}$ ) gives ample scope for this organism to be a prime cause of public health hazard (Griffiths and Schraft 2002).

The distribution of Bacillus cereus is worldwide (Logan and Rodrigez-Diaz 2006). Diseases caused by B. cereus are commonly found in places where there is improper food handling. The prevalence of $B$. cereus induced food-borne illnesses is difficult to determine, because the symptoms associated with $B$. cereus infections or intoxication are mild, so it is conceivable that many $B$. cereus infections are not reported and that the prevalence of these infections is largely under estimated (Granum 2007). B. cereus illness recognized that there may be significant under reporting due to the generally mild, short duration and self-limiting symptoms, in addition to its being infrequently tested for in routine laboratory analyses of stool samples (Hall et al. 2005) and due to lack of effective surveillance, $B$. cereus associated food poisoning may be largely under reported, and probably confused with Staphylococcus aureus and Clostridium perfringens food poisoning due to similar symptoms (Stenfors et al. 2008).

This organism can be detected in a variety of raw milk and milk products especially in vegetative form, which exposed directly in contact with the soil (Bennett and Belay 2001) and produces toxins which caused food borne illness and considered as a significant public health hazard. However, the isolation of high levels of B. cereus was suggested to be involved in food poisoning and causes gastroenteritis motility (Madigan et al. 2009).

The consumption of raw milk and its derivatives is common in Ethiopia, which is not safe for consumer health as it may lead to the transmission of various diseases (Wubete 2004; Shunda et al. 2013). Moreover, from experience of the researchers in Haramaya districts, the consumption of raw milk and milk products was a common practice. However, detailed information on the occurrence and load of Bacillus cereus is limited in the district. Thus, to get information on the pathogen trends, there should be isolation of the organism and profiling of its antibiotic sensitivity patterns. Therefore, the objectives of the study were; to determine the occurrence of Bacillus cereus in raw bulk milk samples collected from market areas at Haramaya district; to evaluate Bacillus cereus load in raw milk samples and assess the susceptibility patterns of Bacillus cereus isolates to commercially available antimicrobials.

\section{Methods}

\section{Study area and materials}

The study was conducted from November 2015 to March 2016 at Haramaya district (Aweday, Haramaya town,
Bate towns) in Eastern Hararghe zone, Ethiopia. The area is located at $2000 \mathrm{~m}$ altitude above sea level and receives $492 \mathrm{~mm}$ average annual rain fall ranging from 118 to $866 \mathrm{~mm}$. The maximum and minimum temperatures are $24{ }^{\circ} \mathrm{C}$ and $9^{\circ} \mathrm{C}$ respectively. Ecologically, the area has $65 \%$ midland and 35\% lowland zones. The two predominant soil types are $60 \%$ rigo soils and $40 \%$ heavy black clay soil. The relative humidity of the area is 65\% (HADB 2014). The study materials were bulk milk samples collected from market areas of the mentioned towns. In the market areas, raw milk was mostly handled by plastic containers with capacity of 3 litters and sellers sat on sides of main access roads to market places which were exposed to dusts from the passengers and vehicles.

\section{Study design and sampling techniques}

A cross-sectional study was carried out to study the occurrence and load of B. cereus and their antimicrobial susceptibility profile in milk samples collected from market places of the study areas. Due to the availability of materials and reagents, the sample size was estimated to consist at least 30 from each subject according to the suggestion given by Singh (2006).

\section{Milk sample collection for microbiology analysis}

Milk samples were collected into sterile bottles aseptically from bulk milk (market). Before taking samples from bulk, the containers were gently homogenized to allow uniform distribution of the constituents in the milk and then taken $10 \mathrm{ml}$ of milk samples using universal bottle. The universal bottles were clearly labeled by water proof ink using coding system for each sample. Finally, the collected samples were kept in ice box and transported to Haramaya University, College of Veterinary Medicine, Microbiology Laboratory and processed up on arrival.

\section{Laboratory analysis of milk samples Bacillus cereus isolation and identification}

Bacillus cereus selective agar base (CM0167, Oxoid) was the media used to isolate vegetative cells of Bacillus cereus from milk samples. The medium was prepared based on egg yolk, mannitol supplementation. The medium was made selective by addition of Polymyxin B Supplement (SR99) which gives a final concentration of 100 IU of polymyxin B per ml of medium. After18-24 h of incubation at $37{ }^{\circ} \mathrm{C}$ in aerobic conditions, the growth of Bacillus cereus was determined based on the colonial morphology, precipitation of hydrolyzed lecithin around colonies and the failure of Bacillus cereus to utilize mannitol sugar according to Mossel et al. (1967) and Fricker et al. (2008). Generally, colonies appearing as crenate, about $5 \mathrm{~mm}$ in diameter and have a distinctive turquoise to peacock blue color surrounded by egg yolk precipitation of the same color were presumptively considered as Bacillus cereus. The 
isolates were confirmed by microscopic examination of Gram's reagent stained smear and biochemical tests. On gram staining Bacillus cereus was expected to appear as Gram-positive (purple colored), rod shaped cells with short to long chains. The growth of other organisms (contaminants) was ruled out by their colonial appearance and bacterial characteristics on gram staining.

\section{Biochemical tests}

Bacillus cereus isolates were tested for different biochemical tests such as, catalase test, oxidase test and oxidation-fermentative test. Due to the selective nature of the media no further tests were conducted as it enables to differentiate the organism based on these tests.

\section{Enumeration of Bacillus cereus}

This was done by preparing serial dilutions from $10^{-1}$ to $10^{-6}$ by transferring $1 \mathrm{ml}$ homogenized sample (1:10 dilution) to $9 \mathrm{ml}$ sterile saline water, mixing well with vigorous shaking and continuing until $10^{-6}$ dilution was reached. The serial dilutions were inoculated in duplicate on Bacillus cereus selective agar base (CM0167, Oxoid) plates with by spreading $0.1 \mathrm{ml}$ onto surface of each plate with sterile glass spreading rod. Plates were incubated for $18-72 \mathrm{~h}$ at $37{ }^{\circ} \mathrm{C}$ and observe for colonies with characteristics of $B$. cereus. As a rule, plates having colonies between 30 and 300 were considered for calculating the number of colonies in each serial dilution. Finally, the number of $\mathrm{CFU} / \mathrm{ml}$ of samples was calculated using the standard equation of Nicoletta and Royston (2008). The bacterial count was interpreted as those having above and below recommended level as described by Council Directives 92/46/EEC (1992). Accordingly, those having $>10^{5} \mathrm{CFU} / \mathrm{ml}$ were recorded as above legal limit.

$$
N=\frac{\sum C}{\left(\mathrm{n}_{1}+0.1 \mathrm{x} \mathrm{n}_{2}\right) \times \mathrm{d}}
$$

Where: $\mathrm{N}=$ total viable colony counts; $\Sigma \mathrm{C}=$ sum of colonies counted from all plates; $\mathrm{n}_{1}=$ number of plates counted at first dilution; $\mathrm{n}_{2}=$ number of plates at second dilution; $\mathrm{C}=$ number of colonies counted; $\mathrm{d}=$ dilution factor from which the first counts obtained (least counted dilution).

\section{Antimicrobial susceptibility test of isolates}

Antibiotic susceptibility tests of $10 \mathrm{~B}$. cereus isolates was performed following the standard agar disk diffusion method according to Quinn et al. (1999) and CLSI (2012) using 10 commercially available antimicrobial disks. Briefly, each isolated bacterial colony from pure fresh culture was transferred into a test tube of $5 \mathrm{ml}$ Tryptone Soya Broth (TSB) (OXOID, England) and incubated at $37^{\circ} \mathrm{C}$ for $6 \mathrm{~h}$. The test broth was adjusted to McFarland 0.5 turbidity to obtain desired bacterial population. Mueller-Hinton agar (Bacton Dickinson and Company, Cockeysville USA) plates were prepared according to the manufacturer guidelines. A sterile cotton swab was immersed into the inoculum suspension and rotated against the side of the tube to remove the excess fluid and then swabbed in three directions uniformly on the surface of Mueller-Hinton agar plates. After the plates dried, antibiotic disks were placed on the inoculated plates using sterile forceps. The antibiotic disks were gently pressed onto the agar to ensure firm contact with the agar surface, and incubated at $35^{\circ} \mathrm{C}$ for $18-72 \mathrm{~h}$. Following this the diameter of inhibition zone formed around each disk was measured using a black surface, reflected light and transparent ruler by lying it over the plates. As there was no specific manual for interpretation of $B$. cereus zone of inhibition, the result was classified as resistance, moderately susceptible and resistant according to the standardized table supplied by Quinn et al. (1999) and CLSI (2012) for Staphylococcus and other organisms (Table 1).

Table 1 Guideline for antimicrobial discs used for susceptibility test of B. cereus with their respective concentrations

\begin{tabular}{|c|c|c|c|c|c|}
\hline \multirow[t]{2}{*}{ Antimicrobial agents } & \multirow[t]{2}{*}{ Symbols } & \multirow{2}{*}{$\begin{array}{l}\text { Disc potency } \\
(\mu \mathrm{g})\end{array}$} & \multicolumn{3}{|c|}{ Zone diameter, nearest whole mm } \\
\hline & & & Resistance $(\leq)$ & Moderate & Susceptible $(\geq)$ \\
\hline Amoxicillin & AML & 20 & 13 & $14-17$ & 18 \\
\hline Ampicillin & AMP & 10 & 28 & - & 29 \\
\hline Cefoxitin & FOX & 30 & 21 & - & 22 \\
\hline Erythromycin & E & 15 & 13 & $14-22$ & 23 \\
\hline Kanamycin & K & 30 & 13 & $14-17$ & 18 \\
\hline Tetracycline & TE & 30 & 14 & $15-18$ & 19 \\
\hline Vancomycin & VA & 30 & 9 & $10-11$ & 12 \\
\hline Doxycycline & $\mathrm{D}$ & 30 & 12 & $13-15$ & 16 \\
\hline Enrofloxacin & ENR & 5 & 15 & $16-20$ & 21 \\
\hline Penicillin & P & 10 unit & 28 & - & 29 \\
\hline
\end{tabular}


Table 2 The prevalence of Bacillus cereus in raw milk from different areas

\begin{tabular}{lllll}
\hline Area & $\begin{array}{l}\text { Number of } \\
\text { samples } \\
\text { examined }\end{array}$ & $\begin{array}{l}\text { Number } \\
\text { of positive } \\
\text { samples }\end{array}$ & $\begin{array}{l}\text { Percentage } \\
\text { prevalence }\end{array}$ & $X^{2}$ (p-value) \\
\hline Aweday & 32 & 15 & 46.9 & 1.7649 (0.414) \\
Haramaya & 41 & 13 & 31.7 & \\
Bate & 30 & 12 & 40 & \\
Total & 103 & 40 & 38.8 &
\end{tabular}

\section{Data management and analysis}

Data collected from laboratory result was stored on Microsoft excel spread sheet program, and analysis was done by using SPSS Version 20 software program. The total prevalence was calculated by dividing the number of $B$. cereus positive milk samples by the total number of milk sample tested. Chi-square test was performed to assess the association of different variables with the occurrence and load of Bacillus cereus. A p-value of less than $0.05(p<0.05)$ was considered as statistically significant association.

\section{Results}

\section{Prevalence of Bacillus cereus}

The overall prevalence of Bacillus cereus in raw bulk milk was $38.8 \%$, and the highest score was recorded from Aweday market followed by Bate and Haramaya town (Table 2). The Statistical analysis in Table 1 below shows origin of milk collected was insignificantly $(p>0.05)$ associated with the positivity of Bacillus cereus.

\section{Bacillus cereus load of raw milk samples}

Majority of raw milk samples (60\%) from the market areas showed bacterial count above the recommended level $\left(>10^{5} \mathrm{CFU} / \mathrm{ml}\right)$ and it was higher in milk samples collected from Bate (83.3\%) as compared to others (Table 3). Based on area of sample collected, the load of B. cereus was not significantly varied $(p>0.05)$. Some of the plates with above recommended level were having bacterial colonies too many to count (Figs. 1 and 2).

Table 3 Bacillus cereus load of raw milk samples collected from different sources

\begin{tabular}{llll}
\hline Area & $\begin{array}{l}\text { Number } \\
\text { of positive } \\
\text { samples }\end{array}$ & $\begin{array}{l}\text { Number of } \\
\text { samples with } \\
\text { above recommended } \\
\text { level }(\%)\end{array}$ & $X^{2}$ (p-value) \\
\hline Aweday & 15 & $9(60)$ & $4.6399(0.098)$ \\
Haramaya & 13 & $5(38.5)$ & \\
Bate & 12 & $10(83.3)$ & \\
Total & 40 & $24(60$ & \\
\hline
\end{tabular}

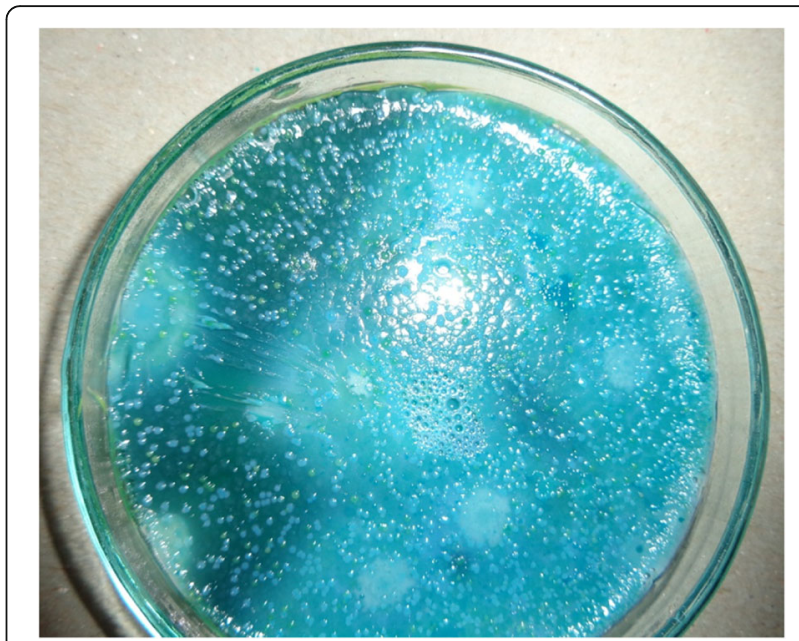

Fig. 1 Bacillus cereus colonies at $10^{-6}$ dilution on Bacillus cereus selective agar

In-vitro antimicrobial susceptibility of isolates

A total of 10 Bacillus cereus isolates were tested for antimicrobial sensitivity against 10 different types of antimicrobial discs (Table 4). The result showed that, all isolates showed 100\% susceptibility to Erythromycin, Vancomycin and Enrofloxacin and majority of isolates (80\%) showed susceptibility towards Doxycycline. On the other hand, $B$. cereus isolates showed high resistance to penicillin (100\%), ampicillin (100\%), amoxicillin (80\%) and cefoxitin (80\%) (Fig. 3).

\section{Discussion}

The present study was conducted on raw milk sample collected from market areas with the objectives; to

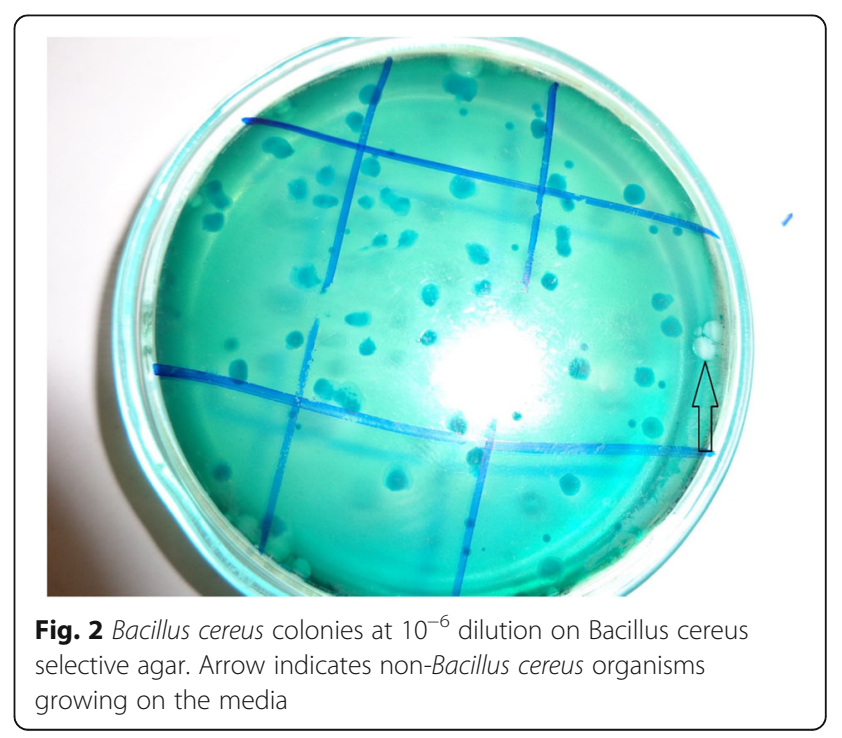


Table 4 Summary of antimicrobial susceptibility profile of Bacillus cereus isolates $(n=10)$

\begin{tabular}{llll}
\hline Antimicrobial & \multicolumn{2}{l}{ Number of isolates } \\
\cline { 2 - 4 } & $\begin{array}{l}\text { Resistant } \\
(\%)\end{array}$ & $\begin{array}{l}\text { Moderately susceptible } \\
(\%)\end{array}$ & $\begin{array}{l}\text { Susceptible } \\
(\%)\end{array}$ \\
\hline Penicillin (P) & $10(100)$ & $0(0)$ & $0(0)$ \\
Ampicillin (AMP) & $10(100)$ & $0(0)$ & $0(0)$ \\
Amoxicillin (AML) & $8(80)$ & $0(0)$ & $2(20)$ \\
Cefoxitin (FOX) & $8(80)$ & $0(0)$ & $2(20)$ \\
Erythromycin (E) & $0(0)$ & $0(0)$ & $10(100)$ \\
Vancomycin (VA) & $0(0)$ & $0(0)$ & $10(100)$ \\
Enrofloxacin (ENR) & $0(0)$ & $0(0)$ & $10(100)$ \\
Kanamycin (K) & $0(0)$ & $8(80)$ & $2(20)$ \\
Tetracycline (TE) & $2(20)$ & $4(40)$ & $4(40)$ \\
Doxycycline (DO) & $0(0)$ & $2(20)$ & $8(80)$ \\
\hline
\end{tabular}

determine $B$. cereus prevalence and evaluate $B$. cereus load in raw milk. The overall prevalence of $B$. cereus in raw bulk milk in Haramaya district was $38.8 \%$. In their study Organji et al. (2015) reported far higher prevalence $(66.6 \%)$ of B. cereus isolated from of raw milk samples in Egypt. This variation could be due to the small sample size examined by the researchers. However, it is evident that milk could serve as good media for human exposure.

This high prevalence of $B$. cereus in milk samples from market areas could be due to improper collection, transportation and handling of the milk as it was observed that almost all personnel's use dirt containers and there is high risk of exposure environmental contamination due to frequent opening and closing of containers. The prevalence of $B$. cereus from bulk milk was higher in Aweday as compared to other districts. But there was no statistically significant difference $(P>0.05)$. This could be due to similar condition under which milk is handled for sale in the districts.

In the present study, the Bacillus cereus load was estimated based on the legal limit which is safe for human consumption. Thus, $60 \%$ of Bacillus cereus positive milk samples were having load above the recommended level. Generally, the prevalence and load of Bacillus cereus was not significantly varied between different factors. This could be due to similar exposure rate and similar patterns of occurrence of the organism in the environment in the districts. Moreover, it is evident that, Bacillus cereus is ubiquitous organism (Bottone 2010).

The present study showed that, B. cereus isolates showed high resistance to penicillin (100\%), ampicillin $(100 \%)$, amoxicillin (80\%) and cefoxitin $(80 \%)$ which is supported by the findings of Luna et al. (2007), who showed that majority of $B$. cereus were resistant to ampicillin (95\%) and penicillin (95\%). This high resistance pattern could be due to irrational and widespread use of few antimicrobials. Agreeably, Organji et al. (2015) from Egypt reported that 100\% of tested isolates showed resistance to Penicillin G. Moreover, concurring the present finding, Organji et al. (2015) reported that, $100 \%$ of tested isolates were susceptible to Erythromycin and Vancomycin.

\section{Conclusion}

The present study presents basic data on the occurrence and load of Bacillus cereus in raw milk ready for market. From the present study report it is evident that, the prevalence of Bacillus cereus was high (38.8\%) and majority $(60 \%)$ of positive samples were having bacterial load above the recommended level for human consumption. The organism showed resistance and

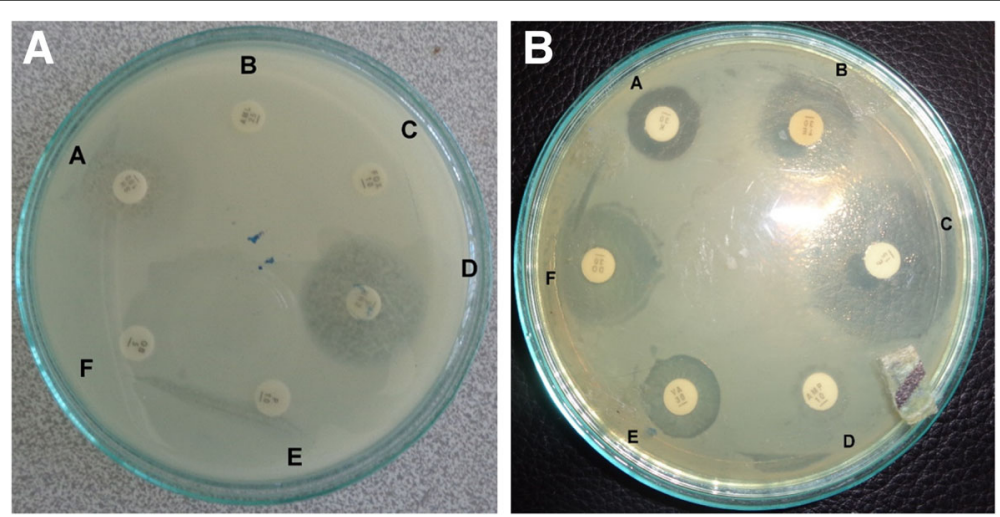

Fig. 3 a from B-E samples of disc diffusion test for Amoxicillin, Cefoxitin, Enrofloxacin, Penicillin; (b) from A-B samples of disc diffusion test for Kanamycin Tetracycline Enrofloxacin, Ampicillin, Vancomycin, Doxycycline. Non-mentioned discs are due to absence standard zone of inhibition for interpretation 
moderate susceptibility to majority $(80 \%)$ of tested antimicrobials. Thus, there could be challenges in the treatment of infections associated with organism. The high prevalence of Bacillus cereus recorded in the markets is quite alarming as these organisms are causative agents of food poisoning and spoilage. Therefore, adequate equipment and facilities for milk storage should be used necessary to minimize microbial contaminations and milk for public consumption should be properly boiled at appropriate temperature.

\section{Acknowledgements}

The authors would like to acknowledge the College of Veterinary Medicine, Haramaya University, for allowing access to Microbiology Laboratory and provision of materials and reagents for the isolation of the organism.

\section{Funding}

There is no fund for the activity. The research was done by the initiation of the Staffs of College of Veterinary Medicine and externship student (for fulfillment of the DVM degree) with the help of Haramaya University Materials and reagents (bacterial media, biochemical test kits, antibiotic discs)

\section{Availability of data and materials}

All necessary data supporting our findings can be found in the repository.

\section{Authors' contributions}

AA carried out the conception of the research concept and designed the methodology, data analysis and interpretation and preparation of the manuscript for publication. TB and SA carried out the sample collection and laboratory work and revision of the manuscript. YM give critical comment on the proposal methodology and reviewed the manuscript for publication. All authors read and approved the final manuscript.

\section{Authors' information}

AA: Doctor of Veterinary Medicine (DVM), MSc in Veterinary Microbiology, Assistant Professor at College of Veterinary Medicine, Haramaya University. TB: Doctor of Veterinary Medicine (DVM). SA: Bachelor of Veterinary Science, Lecturer at College of Veterinary Medicine, Haramaya University. YM: Veterinary laboratory technologist (VLT), MSc in Veterinary Microbiology, Lecturer at College of Veterinary Medicine, Haramaya University.

\section{Ethical approval and consent to participate}

There was no involvement of animals and humans for sample taking as the study was conducted on milk samples taken from containers which were ready for sale on non-standardized market systems.

\section{Consent for publication}

In our study, we don't have individual participants image, video, etc.

\section{Competing interests}

The authors declare that there is no financial or non-financial competing interest from anybody or institute. We also want to assure that we did not receive any technical assistant in developing the research concept or preparation of the manuscript.

\section{Publisher's Note}

Springer Nature remains neutral with regard to jurisdictional claims in published maps and institutional affiliations.

\section{Author details}

${ }^{1}$ Haramaya University College of Veterinary Medicine, P.O. Box 138, Dire Dawa, Ethiopia. ${ }^{2}$ Oromiya Region, Bale zone, Dinsho Woreda Livestock and Fishery Office, Dinsho, Ethiopia.
Received: 31 August 2017 Accepted: 23 October 2017

Published online: 26 October 2017

\section{References}

Bennett RW, Belay N. bacillus cereus. In: Downes FP, Ito K, editors. Compendium of methods for the microbiological examination of foods. Washington: American Public Health Association; 2001. p. 311-6.

Bottone EJ. Bacillus cereus, a volatile human pathogen. Clinic Microbiology Rev. 2010:23(2):382-98.

Ceuppens S, Boon N, Uyttendaele M. Diversity of Bacillus cereus group strains is reflected in their broad range of pathogenicity and diverse ecological lifestyles. FEMS Microbiol Ecol. 2013;84(3):433-50.

CLSI. Document M100-S22, performance standards for antimicrobial susceptibility testing: twenty second informational supplement. Wayne: CLSI; 2012.

Council Directives 92/46/EEC. Laying down the health rules for production and placing on the market of raw milk, heat-treated milk and milk based products. Officals J Eur. Communities. 1992:1268.

Fricker M, Reissbrodt R, Ehling-Schulz M. Evaluation of standard and new chromogenic selective plating media for isolation and identification of Bacillus cereus. Int J food Micro. 2008:121(1):27-34.

Granum PE. Bacillus cereus. Food borne pathogens: microbiology and molecular biology. Norfolk: Caister Academic Press; 2005. p. 409-19.

Granum PE. Bacillus cereus. Food microbiology: fundamentals and Frontiers. In: Beuchat LR, editor. Doyle MP. Washington, DC: ASM Press; 2007. p. 445-55.

Griffiths W, Schraft H. Bacillus cereus food poisoning. In: Cliver DO, Riemann HP, editors. Food borne diseases. London: Academic Press; 2002. p. 261-70.

HADB Haramaya agricultural and development bureau (2014). Database.

Hall G, Kirk MD, Becker N, Gregory JE, Unicomb L, Millard G, Stafford R, Lalor K. Estimating foodborne gastroenteritis, Australia. Emerg Infect Dis. 2005;11(8): 1257-64.

Hong HA, DucLe H. Cutting SM. The use of bacterial spore formers as probiotics. FEMS. Microbiol Rev. 2005;29(4):813-35.

Logan NA, Rodrigez-Diaz M. Bacillus spp. and related genera. In: Gillespie SH, Hawkey PM, editors. Principles and practice of clinical bacteriology, vol. 10. 2nd ed. West Sussex: John Wiley and Sons Ltd; 2006. p. 261-86.

Luna VA, King DS, Gulledge J, Cannons AC, Amuso PT, Cattani J. Susceptibility of Bacillus anthracis, Bacillus cereus, Bacillus mycoides, Bacillus pseudomycoides and Bacillus thuringiensis to 24 antimicrobials using Sensititre automated microbroth dilution and Etest agar gradient diffusion methods. J Antimicrob Chemother. 2007;60:555-67.

Madigan MT, Martinko JM, Dunlap PV, Clark DP. Brock biology of microorganisms. In: Food preservation and food borne microbial diseases. 12th ed. San Francisco: Pearson International; 2009. p. 1043-61.

Mossel DAA, Koopman MJ, Jongerius E. Enumeration of Bacillus cereus in foods. J Appl Micro. 1967;15(3):650-3.

Organji SR, Abulreesh HH, Elbanna K, Osman GEH, Khider M. Occurrence and characterization of toxigenic Bacillus cereus in food and infant feces. Asian Pac J Trop Biomed. 2015:5(7):515-20.

OSPBH. Opinion of scientific panel on biological hazards (OSPBH) on Bacillus cereus species in food stuffs. Journal. EFSA. 2005:175:1-48.

Quinn J, Carter E, Markey B, Carter R. Clinical veterinary microbiology. Philadelphia: Elsevier Limited; 1999. p. 118-36.

Shunda D, Habtamu T, Endale B. Assessment of bacteriological quality of raw cow milk at different critical points in Mekelle, Ethiopia. Int J Livestock Res. 2013:3(4):42-8.

Singh YK. Fundamentals of Research Methodology and Statistics. Daryaganj: New age international (P) Ltd., Publishers; 2006. p. 93-4.

Stenfors ALP, Fagerlund A, Granum PE. From soil to gut: Bacillus cereus and its food poisoning toxins. FEMS Microbiol Rev. 2008;32(4):579-606.

TeGiffel MC, Beumer RR, Slaghuis BA, Bombouts FM. Occurrence and characterization of (psychrotrophic) Bacillus cereus on farms. the dairy J. 1995:49:125-38.

Wubete A. Bacteriological quality of bovine milk in small holder dairy farms in Debre-Zeit. Ethiopia: MSc.Thesis Faculty of Veterinary Medicine, Addis Ababa University; 2004 